\title{
Clicks, Whoops, and Honks ${ }^{\star}$
}

\author{
DOUGLAS PICKERING \\ From the Departments of Paediatrics and Cardiology, Radcliffe Infirmary, Oxford
}

\begin{abstract}
Pickering, D. (1972). Archives of Disease in Childhood, 47, 731. Clicks, whoops, and honks. 5 children are described with the midsystolic click-systolic murmur syndrome, sometimes accompanied by honks or whoops. The characteristic variation in auscultatory findings with posture is shown. The theory as to the mechanism of production of these findings is described, together with their aetiologies, prognosis, and treatment.
\end{abstract}

Whoops were named by McKusick in 1958 to describe intermittent loud, sonorous, vibratory murmurs heard in late systole at the apex, and usually preceded by mid-late systolic click. He called them whoops because they sounded like the whoop of whooping cough. Rackley et al. (1966), hearing the same sounds, called them honks because to them they sounded like the honking of wild geese. These sounds, together with apical late systolic murmurs are caused by late systolic mitral valve regurgitation associated with prolapsing mitral valve leaflets into the left atrium (Ehlers et al., 1970; Behar, Whalen, and McIntosh, 1967). This paper describes 5 further cases of this type of mitral valve dysfunction, their associated clinical features, and how the auscultatory findings characteristically vary with posture. A 'Pixie' accelerometer (Bew et al., 1971) was used to record the phonocardiograms.

An accelerometer is a small transducer which senses the acceleration of any object to which it is attached. It usually consists of a small bob-weight supported on a cantilever spring. Upward acceleration at the base causes a downward movement of the bob relative to the base of a magnitude dependent on the mass of the bob, the stiffness of the spring, and proportional to the acceleration applied to the base. The amplitude of vibrations due to events generating sound is obviously very small, but for a given amplitude of sinusoidal vibration the acceleration is proportional to the square of the frequency, so that vibrations in the audible frequency range, which cannot be detected by a displacement measuring device, may be detected by an accelerometer. With an accelero-

Received 28 February 1972.

*Part of this work was supported by funds from the Ontario Heart Foundation and the Wellcome Travel Fund. meter applied to a chest wall, the vibrations at that particular spot are converted directly and quantitatively into an electrical signal. A series of band pass filters was introduced to remove the low frequency components of the praecordial acceleration trace leaving behind the audio-frequencies to produce a phonocardiogram.

\section{Case Reports}

Case 1. A boy aged 9 years was noted to have a murmur at the age of 3 months on routine examination in the Child Welfare Clinic. At 5 years he was noted to have a thrill and pansystolic murmur at the lower left sternal border conducted to the axilla, together with an accentuated and delayed pulmonary second sound. The chest $x$-ray and ECG were normal. Right heart catheterization showed normal pressures and saturations. A right ventricular angiocardiogram and subsequent laevocardiogram revealed no abnormality. It was concluded that he had a small ventricular septal defect and no surgical treatment was indicated. In Oxford, at 9 years of age, 'Pixie' phonocardiography confirmed the auscultatory findings shown in Fig. 1. In the lying position, medial to the apex, was a long systolic murmur with a late systolic click occurring $0.33 \mathrm{sec}$ after the $Q$ wave of the ECG. On standing (Fig. 2), the murmur shortened and the click moved to $0 \cdot 19$ sec after $Q$. On squatting from this position (Fig. 3) the murmur and Q-click gap lengthened to 0.37 sec. On standing once more (Fig. 4), the Q-click gap shortened to $0.21 \mathrm{sec}$. The remainder of the physical examination was normal.

Case 2. A girl of 11 years was noted to have a murmur at routine school medical examination at the age of 7 . She was noted to have the features of Marfan's syndrome and a clinical diagnosis of pulmonary stenosis was made. She has two normal sisters and her father is unknown. Physical examination (Fig. 5) showed a thin child, 25th centile for weight and 75th centile for height. Span was $151 \mathrm{~cm}$ and height $147 \mathrm{~cm}$. Crown to pubic 


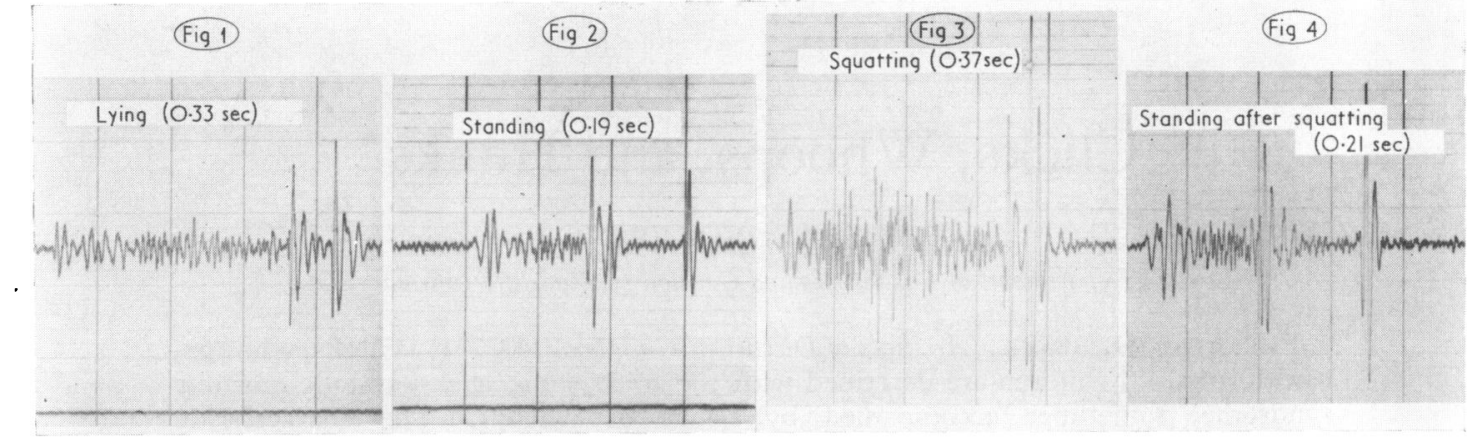

FIG. 1-4.-Phonocardiograms of Case 1. (1) Lying down; long systolic murmur and late click $0 \cdot 33$ sec. after $Q$ of ECG. (2) Standing; short early systolic murmur and midsystolic click 0.19 sec. after $Q . \quad$ (3) Squatting from standing in Fig. 2; murmur returns to long duration with late click. (4) Standing after squatting, showing return to pattern in Fig. 2.

length $67 \mathrm{~cm}$, pubis to ground $78 \mathrm{~cm}$. Her arms extended below midthigh; she had long hyperextensible fingers and feet, a scoliosis concave to the right, and a high arched palate. Her eyes were normal. She had a short early systolic murmur and midsystolic click moving with posture in the same manner as Case 1 . The metacarpal index was $9 \cdot 4$. Chest $x$-ray showed scoliosis but was otherwise normal. Blood picture, ECG and exercise ECG, amino acids, and mucopolysaccharides in the urine were normal.

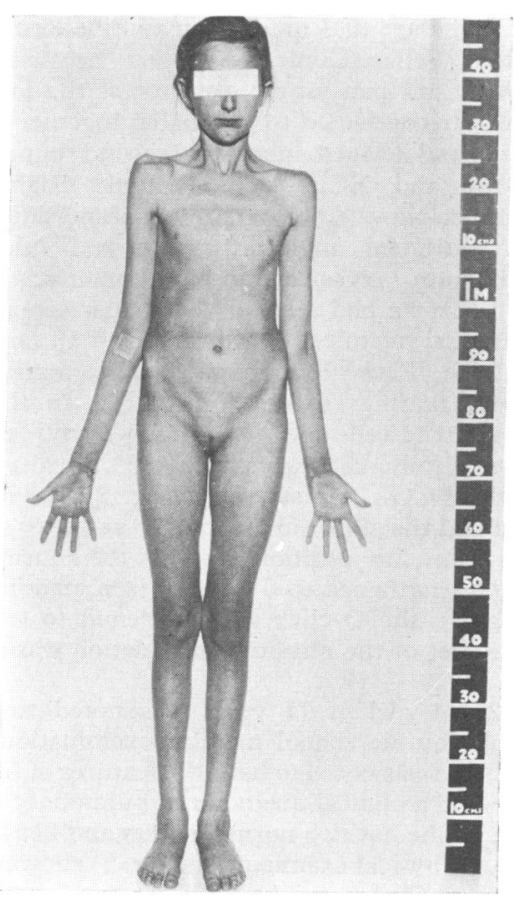

Fig. 5.-Case 2. Marfan type of habitus.
Case 3. A boy, aged 12 years, presented with a 4 -year history of 'squeak in the chest' coming on with exercise or when he was nervous. He was otherwise symptom free. Clinical examination at rest showed no abnormality. On standing, a grade $1 / 4$ ejection systolic murmur and a very soft midsystolic click were heard medial to the apex. However, on exercise he developed a loud praecordial 'honk' which was audible without a stethoscope and which varied considerably with respiration, being maximal at the end of inspiration (Fig. 6). His chest $x$-ray, ECG, and exercise ECG were normal.

Case 4. A child aged 11 years with meningomyelocele was noted to have a cardiac murmur when admitted for neurosurgery. Physical examination showed a pectus excavatum and an apical grade $2 / 4$ late systolic murmur of a honking character which increased on inspiration. In addition there was an intermittent midsystolic click at the lower left sternal border. Chest $x$-ray was normal and ECG showed mild left ventricular hypertrophy.

Case 5. A girl of 12 years, a proven case of Marfan's syndrome, was admitted for correction of scoliosis and noted to have a murmur on routine examination. She had a honking high-pitched grade $2 / 4$ vibratory systolic murmur along the left sternal border and at the apex. There was a loud apical systolic click which moved with posture, as shown in Case 1. The ECG and chest $x$-ray were normal.

\section{Discussion}

Late systolic murmurs, honks, and whoops were thought to be innocent, and mid-late systolic clicks were considered to be extracardiac in origin until recently. However, Griffith in 1892 suggested that a musical late systolic murmur denoted mitral incompetence, and Paul White (1944) proposed that midsystolic clicks arose from the chordae tendineae. The pleuropericardial theory of their origin remained widespread until 1961 when Reid 


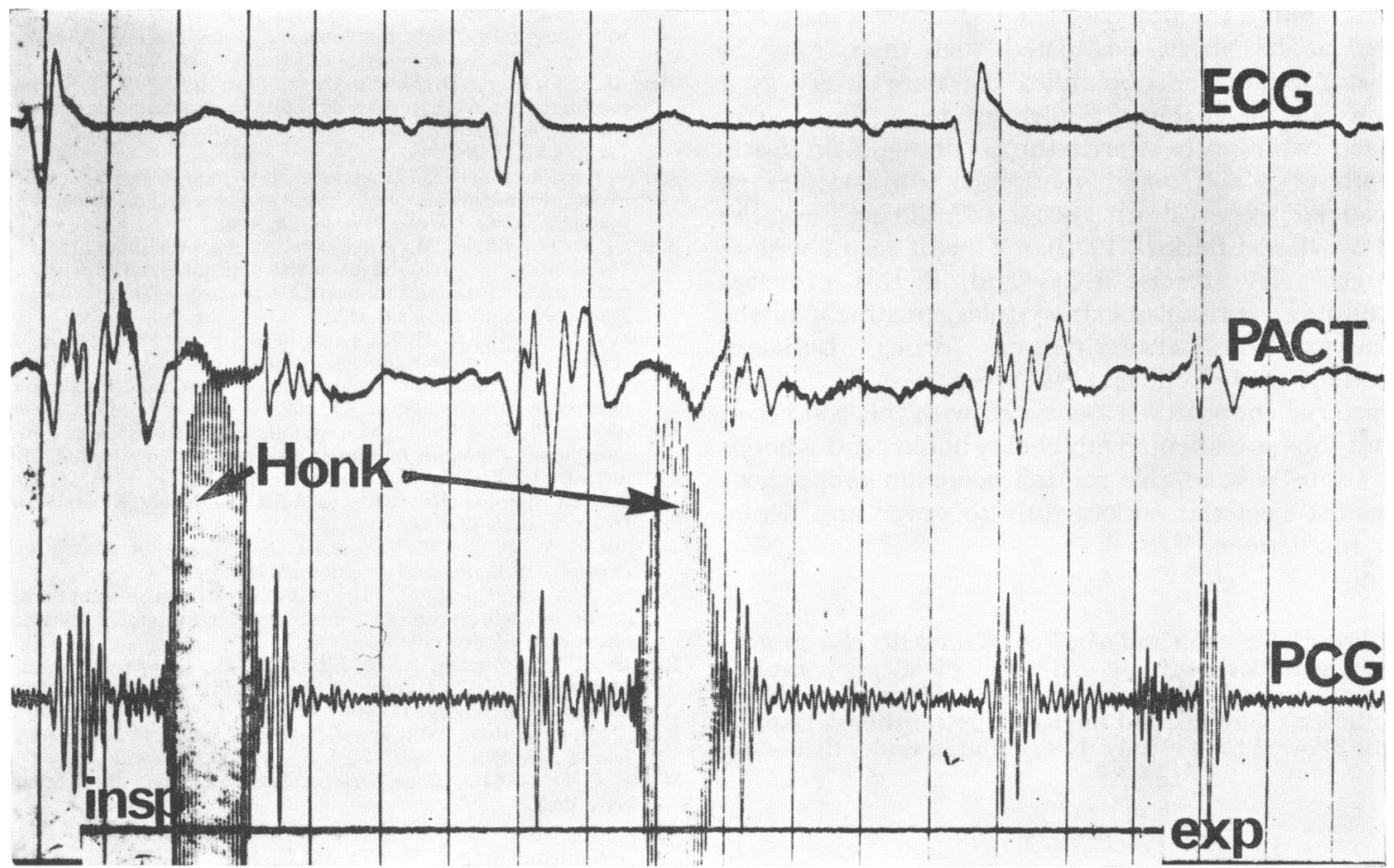

FIG. 6.-Case 3. Praecordial honk or whoop after exercise, maximal on inspiration and disappearing on expiration.

suggested that both the apical midsystolic click and late systolic murmurs were of mitral valvular origin, and he speculated that elongated or redundant chordae or inadequate papillary muscle contraction could result in flattening of the chordae in midsystole at which time the high left ventricular/left atrial pressure gradient could snap a slack chorda taut producing a click, the 'chordal snap'. The attached valve could be either competent with no murmur or incompetent producing a late systolic murmur or honk. Barlow et al. (1968) showed mitral incompetence on left ventricular angiocardiograms of 7 patients with late systolic murmurs. Criley et al. (1966) in an elegant study correlating ECG's and intracardiac phonocardiograms with cineangiocardiograms showed that the systolic click coincided with the time of maximal valve prolapse. Fontana et al. (1970) described the striking variations in systolic clicks and late systolic murmurs with changes in posture, that mid- or late systolic clicks moved towards the first heart sound during sitting up or standing, and with prompt squatting returned to their original position. Honks or whoops in these cases may only appear on standing or exercise. The explanation offered was that as the click occurs at the time of maximal valve prolapse, click movement towards the first heart sound suggests early prolapse in the erect position. The left ventricular end-diastolic volume is smaller in the erect posture, the mitral valve cusps are then closer to the position of prolapse, and the small end-diastolic volume exaggerates the amount of prolapse with the onset of contraction. Supporting this is the response to squatting which is known to increase the left ventricular end-diastolic volume when the click becomes late.

These auscultatory findings may have several causes. They may be secondary to myxomatous degeneration of the mitral cusps, the 'ballooned or floppy valve' syndrome, elongated or improperly attached chordae tendineae, Marfan's or Marfan-like syndromes affecting the connective tissue of these structures, possible papillary muscle involvement in severe congenital aortic stenosis, anomalous left coronary artery from the pulmonary artery, or to some forms of myocarditis (Fontana et al., 1970). The underlying ventricular muscle itself may be involved as in the contraction ring of Engel where the papillary muscle is pushed up into the ventricular cavity during systole, causing temporary relaxation of the chordae (Ehlers et al., 1970).

Though the primary condition has previously been reported to be benign, it is not entirely innocent as it may be associated with $T$ wave 
inversion in the posterior leads (Barlow et al., 1968) and it has been postulated that there may be distortion of the circumflex coronary artery as it runs in the atrioventricular groove. There have been two reports of arrhythmias and sudden death, both of which noted ventricular extrasystoles on exercise; one death occurred during exercise (Pocock and Barlow, 1970). Thus it seems wise to suggest an exercise ECG and, if this provokes multiple ventricular extrasystoles, treatment of the patient with antiarrhythmic drugs. LeBauer, Perloff, and Keliher (1967) reported 3 cases of bacterial endocarditis associated with this condition, and thus in patients with clicks, honks, and whoops it seems wise to give routine penicillin prophylaxis against bacterial endocarditis to cover any dental manipulations.

I thank Dr. Stott and Mr. Bew of the MRC Electronics Unit who designed and built the 'Pixie' phonocardiogram, also the Consultants at the Hospital for Sick Children, Toronto, and the Radcliffe Infirmary, Oxford, who allowed me to study these children under their care.

\section{REFERENCES}

Barlow, J. B., Bosman, C. K., Pocock, W. A., and Marchand, P. (1968). Late systolic murmurs and non-ejection ('mid-late') systolic clicks. British Heart fournal, 30, 203.
Behar, V. S., Whalen, R. E., and McIntosh, H. D. (1967). The ballooning mitral valve in patients with the 'precordial honk' or 'whoop'. American fournal of Cardiolog.v, 20, 789.

Bew, F. E., Pickering, D., Sleight, P., and Stott, F. D. (1971). 'Pixie' cardiography; accelerometer applications to phonocardiography and displacement cardiography in childhood. British Heart fournal, 33, 702.

Criley, J. M., Lewis, K. B., Humphries, J. O., and Ross, R. S. (1966). Prolapse of the mitral valve: clinical and cine-angiocardiographic findings. British Heart fournal, 28, 488.

Ehlers, K. H., Engle, M. A., Levin, A. R., Grossman, H., and Fleming, R. J. (1970). Left ventricular abnormality with late mitral insufficiency and abnormal electrocardiogram. American fournal of Cardiology, 26, 333.

Fontana, M. E., Pence, H. L., Leighton, R. F., and Wooley, C. F. (1970). The varying clinical spectrum of the systolic clicklate systolic murmur syndrome: a postural auscultatory phenomenon. Circulation, 41, 807.

Griffith, J. P. C. (1892). Mid-systolic and late-systolic mitral murmurs. American fournal of the Medical Sciences, 104, 285.

LeBauer, E. J., Perloff, J. K., and Keliher, T. F. (1967). The isolated systolic click with bacterial endocarditis. American Heart fournal, 73, 534.

McKusick, V. A. (1958). Cardiovascular Sound in Health and Disease. Williams and Wilkins, Baltimore.

Pocock, W. A., and Barlow, J. B. (1970). Postexercise arrhythmias in the billowing posterior mitral leaflet syndrome. American Heart fournal, 80, 740.

Rackley, C. E., Whalen, R. E., Floyd, W. L., Orgain, E. S., and McIntosh, H. D. (1966). The precordial honk. American fournal of Cardiology, 17, 509.

Reid, J. V. O. (1961). Mid-systolic clicks. South African Medical fournal, 35, 353.

White, P. D. (1944). Heart Disease, 3rd ed., p. 65. Macmillan, New York.

Correspondence to Dr. D. Pickering, The Department of Paediatrics, The Radcliffe Infirmary, Oxford OX2 $6 \mathrm{HE}$. 